\title{
Immunohistochemical quantification of substance $P$ in spinal dorsal horns of patients with multiple system atrophy
}

\author{
Naoyuki Tomokane, Tetsuyuki Kitamoto, Jun Tateishi, Yuji Sato
}

\begin{abstract}
Using a computer-assisted image analyser, an immunohistochemical quantification method of substance P-like immunoreactivity (SPLI) in laminae I + II of spinal dorsal horn was established and applied to 13 patients with multiple system atrophy (MSA) with no disturbance of pain sensation, including olivoponto-cerebellar atrophy and striatonigral degeneration, and 13 neurologically normal controls. To investigate whether alteration of SPLI is related to an autonomic disorder, myelinated fibre counts of the fourth thoracic ventral roots were performed. Eleven of $13 \mathrm{MSA}$ patients showed a significant decrease in small and large myelinated fibres, and were diagnosed with definite Shy-Drager syndrome (SDS), with the exception of two who had no apparent history of autonomic dysfunction. SPLIs in laminae $I+I I$ in 10 of these 11 patients, when adjusted for age, were significantly decreased at both levels of the fourth thoracic and third lumbar spinal segments. The results suggest the disorder of SP-containing synapses of primary afferent neurons and/or those of interneurons in SDS.
\end{abstract}

The neuropeptide substance $\mathrm{P}(\mathrm{SP})$ has been suggested as a nociceptive neurotransmitter ${ }^{12}$ or a neuromodulator ${ }^{34}$ of primary afferent neurons. A marked depletion of SP-like immunoreactivity (SPLI) in the superficial laminae of the dorsal horn was reported in several conditions: dorsal rhizotomy, ${ }^{5}$ capsaicin treatment $^{67}$ and peripheral nerve lesions. ${ }^{89}$ Most of the SP in the superficial dorsal horn may be contained in the central terminals of unmyelinated C-fibres of small diameter cells in the dorsal root ganglia. Nociceptive information is relayed to both lamina $I$ and the outer layer of lamina II, ${ }^{1011}$ and to a lesser extent to the inner layer of lamina II. ${ }^{11}$ This localisation pattern of SP has been supported by a number of immunohistochemical studies showing the strongest immunoreactions in lamina I and dorsal parts of lamina II. ${ }^{1213}$ On the grounds that SP antigenicity can be retained in formaldehydefixed and paraffin-embedded specimens for many years, ${ }^{14}$ a quantitative immunohistochemistry for SP in the laminae I + II can be available for evaluation of synapses containing SP of both intrinsic and extrinsic origin.

Shy-Drager syndrome (SDS) $)^{15}$ is character- ised by the autonomic failure, such as orthostatic hypotension, urinary incontinence, inability to perspire, and sexual impotence, attributable to loss of preganglionic cells in the intermediolateral nuclei (IML). ${ }^{16}$ Since this syndrome frequently shows widespread neuronal degeneration in the striatonigral system, locus ceruleus, pontine nuclei, inferior olive and cerebellar cortex, ${ }^{17}$ it is therefore classified as multiple system atrophy (MSA).$^{18}$ Several morphometric studies on thoracic ventral roots of the patients with SDS have shown that small myelinated fibres decrease significantly in number as an explanation of autonomic dysfunction. ${ }^{19} 20$ Although unmyelinated fibres compose a large part of the autonomic pathway, only comparatively few studies have been done concerning the affection of peripheral unmyelinated fibres in SDS. ${ }^{2122}$

In this study, patients with MSA were first divided into two classes either with or without autonomic disorders by their clinical and pathological findings, as well as morphometric features of the thoracic ventral roots. Secondly, after evaluating the effects of necropsy delay on SP immunostain, an optimal condition for the SP immunohistochemistry and a quantification method for image analysis were established and then applied to those patients and controls.

\section{Materials and methods \\ Patients}

Necropsies were carried out on 13 patients with MSA, all with olivo-ponto-cerebellar atrophy (OPCA), 10 with striato-nigral degeneration (SND) (table 1), and 13 age matched controls without neurological disorder (table 2). There was no definite loss of pain sensation in any of the patients. Maximal intervals between death and beginning of necropsy were 11 and 14 hours. After a maximal length of 24 or 25 days fixation by $10 \%$ neutralised formalin in each group, the sixth cervical (C6), fourth thoracic (T4) and third lumbar (L3) segments of the spinal cord were excised, embedded in paraffin and cut into $7 \mu \mathrm{m}$ transverse sections. Serial sections were processed for $\mathrm{HE}$, KlüverBarrera's (KB) stains and SP immunohistochemistry.

The sampling and processing of morphometry of the $\mathrm{T} 4$ ventral roots were performed according to the Low and Dyck method. ${ }^{23}$ The transverse fascicular area and the diameter distribution of myelinated fibres per root were measured in photographs magnified to $\times 100$ 


\begin{tabular}{|c|c|c|c|c|c|c|c|c|c|c|c|}
\hline \multirow[b]{2}{*}{ Case } & \multirow[b]{2}{*}{ Age } & \multirow[b]{2}{*}{ Sex } & \multirow[b]{2}{*}{$P I$} & \multirow[b]{2}{*}{ Fix $L$} & \multicolumn{2}{|c|}{ Duration } & \multicolumn{3}{|c|}{ Autonomic sign } & \multicolumn{2}{|c|}{ Pathology } \\
\hline & & & & & $F T$ & $A D$ & $\mathrm{OH}$ & $V R D$ & $A H$ & $O P C A$ & $S N D$ \\
\hline $\begin{array}{ll}\text { M } & 1 \\
\text { M } & 2 \\
\text { M } & 3 \\
\text { M } & 4 \\
\text { M } & 5 \\
\text { M } & 6 \\
\text { M } & 7 \\
\text { M } & 8 \\
\text { M } & 9 \\
\text { M10 } \\
\text { M11 } \\
\text { M12 } \\
\text { M13 } \\
\text { Mean }\end{array}$ & $\begin{array}{l}44 \\
51 \\
52 \\
57 \\
59 \\
61 \\
61 \\
62 \\
63 \\
64 \\
68 \\
72 \\
73 \\
60 \cdot 3\end{array}$ & $\begin{array}{l}\mathbf{F} \\
\mathbf{F} \\
\mathbf{F} \\
\mathbf{M} \\
\mathbf{F} \\
\mathbf{M} \\
\mathbf{F} \\
\mathbf{F} \\
\mathbf{F} \\
\mathbf{M} \\
\mathbf{F} \\
\mathbf{M} \\
\mathbf{F}\end{array}$ & $\begin{array}{c}7 \\
10 \\
4 \cdot 5 \\
5 \cdot 5 \\
4 \\
8 \\
11 \\
3 \\
3 \\
7 \cdot 5 \\
9 \\
10 \\
5 \\
6 \cdot 7\end{array}$ & $\begin{array}{l}23 \\
14 \\
18 \\
20 \\
21 \\
24 \\
18 \\
19 \\
10 \\
14 \\
19 \\
21 \\
\text { ND } \\
18 \cdot 4\end{array}$ & $\begin{array}{c}3 \\
9 \\
13 \\
4 \\
8 \\
5 \\
7 \\
6 \\
7 \\
6 \\
8 \\
5 \\
6 \\
6.9\end{array}$ & $\begin{array}{ll}1, & 6 \\
4, & 0 \\
3, & 7 \\
6, & 2 \\
5, & 0 \\
3, & 9 \\
4, & 0 \\
5, & 10 \\
2, & 0 \\
5, & 6 \\
4, & 2\end{array}$ & $\begin{array}{l}- \\
+ \\
\text { ND } \\
+ \\
+ \\
+ \\
+ \\
+ \\
+ \\
+ \\
+ \\
+ \\
\text { ND }\end{array}$ & $\begin{array}{l}+ \\
+ \\
+ \\
+ \\
+ \\
+ \\
+ \\
+ \\
+ \\
+ \\
+ \\
+ \\
+\end{array}$ & $\begin{array}{l}\text { ND } \\
\text { ND } \\
\text { ND } \\
\text { ND } \\
+ \\
+ \\
+ \\
\text { ND } \\
- \\
+ \\
\text { ND } \\
+ \\
+\end{array}$ & $\begin{array}{l}+ \\
+ \\
+ \\
+ \\
+ \\
+ \\
+ \\
+ \\
+ \\
+ \\
+ \\
+ \\
+\end{array}$ & $\begin{array}{l}+ \\
+ \\
+ \\
-\mathbf{a} \\
+ \\
+ \\
+ \\
+ \\
- \\
+ \\
+ \\
+ \\
+\end{array}$ \\
\hline
\end{tabular}

PI: postmortem interval (hours); Fix L: fixation length (days); FT: full term (years); AD: duration of autonomic dysfunction (years, months); OH: orthostatic hypotension; VRD: vesicorectal disturbance including dysuria, urinary incontinence and constipation; AH: anhidrosis; Pathology: complicated pathological diagnosis; OPCA: olivo-ponto-cerebellar atrophy; SND: striato-nigral degeneration; ND: not described in necropsy record; a: mild gliosis without neuronal loss.

Table 2 Age-matched controls

\begin{tabular}{llllcl}
\hline Case & Age & Sex & Cause of death & PI & Fix L \\
\hline C 1 & 42 & M & Acute renal failure & $5 \cdot 5$ & 21 \\
C 2 & 49 & F & Cardiac & 3 & 16 \\
C 3 & 52 & M & Pulmonary bleeding & 2 & 16 \\
C 4 & 53 & F & Head trauma & 12 & 18 \\
C 5 & 58 & M & Sudden death & $2 \cdot 5$ & 19 \\
C 6 & 61 & M & Subarachnoid haemorrhage & 10 & 16 \\
C 7 & 65 & F & Subarachnoid haemorrhage & 14 & 17 \\
C 8 & 69 & F & Suicide & 4 & 25 \\
C 9 & 71 & M & Acute abdomen & 5 & 24 \\
C10 & 71 & F & Subarachnoid haemorrhage & 3 & 22 \\
C11 & 73 & M & Acute renal failure & 2 & 18 \\
C12 & 78 & F & Head trauma & $4 \cdot 5$ & 20 \\
C13 & 82 & F & Cardiac & 13.5 & 17 \\
Mean & $63 \cdot 4$ & & & $6 \cdot 2$ & $19 \cdot 2$ \\
\hline
\end{tabular}

PI: postmortem interval (hours); Fix L: fixation length (days).

and $\times 1000$, respectively. According to the diameter distributions in the control study, the division point between large and small myelinated fibres was determined at $6 \cdot 16 \mu \mathrm{m}$.

Adult rats (Sprague-Dawley; 230-250 g; $\mathrm{n}=47$ ) were decapitated under deep anaesthesia with diethyl ether and were kept at $4^{\circ} \mathrm{C}$. At six different intervals $(0,2,4,8,16$ and 24 hours) the lumbar spinal cord segments were excised and immediately immersed in $10 \%$ neutralised formalin for two days at room temperature. The fifth lumbar segments were dissected and processed in the same manner as the human materials.

Polyclonal anti-SP antibody was raised in a New Zealand white rabbit against synthetic SP (Peptide Institute, Osaka, Japan), which was conjugated to bovine serum albumin (BSA) with carbodiimide as a coupling agent according to Chopra. ${ }^{24} \mathrm{An}$ anti-SP titre was raised to 1:12 800 dilution against $70 \mathrm{ng}$ synthetic SP by dot blotting immunoassay (Promega Biotec, Madison). Antiserum specificity was tested with both preabsorbed serum and affinitypurified antibody. Immunostaining was abolished by the preabsorption of the antibody with synthetic SP $(5 \mu \mathrm{g} / 1 \mathrm{ml} \mathrm{SP}$ antiserum). Affinity-purified antibody, which was prepared from the whole SP antiserum by the method of Talian et $a l,{ }^{25}$ differentiated the SP in the dorsal horn of the spinal cord less strongly than the whole SP antiserum while distribution of the immunostained vesicles was similar to each other. Control sections stained with preimmune serum showed no positive stain.
Immunostaining was performed using the whole SP antiserum.

After removing the paraffin, the tissue sections were pretreated with $0.3 \% \mathrm{H}_{2} \mathrm{O}_{2}$ for 30 minutes to reduce non-specific staining by endogenous peroxidases. The unlabelled antibodies biotin-streptavidin method (Stravigen, BioGenix Laboratories, Dublin, $\mathrm{CA})$ was applied. After washing with $\mathrm{PB}(0 \cdot 1 \mathrm{M}$ phosphate, $0.5 \mathrm{M} \mathrm{NaCl}, \mathrm{pH} 7 \cdot 3$ ), the sections were incubated for two days at $4^{\circ} \mathrm{C}$ with diluted anti-SP containing $0 \cdot 2 \%$ Triton $\mathrm{X}-100$. After washing with $P B$, the tissue sections were exposed with biotinylated anti-rabbit IgG antibodies and streptavidin-horseradish peroxidase complex for three hours each, at room temperature. Diaminobenzidine tetrahydrochloride (DAB) containing $\mathrm{H}_{2} \mathrm{O}_{2}$ was used to develop the colour.

To obtain a high contrast between SPspecific immunoreactive products and the surrounding background in light microscopic image analysis, optimal immunohistochemical conditions were examined according to the method proposed by Gross. ${ }^{26}$ As major effective variables, antibody dilution (1/8000-1/250), DAB concentration $(0.002-0.05 \%), \mathrm{H}_{2} \mathrm{O}_{2}$ concentration $(0.0005-0.05 \%)$ and reaction time in DAB (1-10 min) were altered independently. Consecutive serial sections of the L3 segment of a control (C11) was used for this purpose. To avoid any misinterpretation during image analysis, no counterstain was done.

A computer-assisted image analyser (IBAS II, Kontron) was used for quantification of SPspecific immunoreactive products. After appropriately setting the detection threshold, the total area occupied by these products (immunostained area) in the whole area of laminae I + II (reference area) was extracted from the background. The percentage of the immunostained area versus the reference area was calculated (\% Ia) and those of the bilateral dorsal horn were averaged. Because the borderline between lamina II and III could not be directly ensured on the immunohistochemical preparation without counter stain, the reference area was determined from its neighbouring $\mathrm{KB}$ preparation as follows: a digitised image of the dorsal horn, which was obtained from the KB preparation at each level of the spinal segments through a videomicro- 
Figure 1 Schematic illustrations in set of reference area at the level of the L3 cord segment. Reference area necessary to immunohistochemical quantification $(A)$ was obtained by transforming the contour of laminae I + II circumscribed by the tot of arrow heads in the neighbouring section with $K B$ stain $(B)$. The areas occupied by large vessels and fibre bundles were excluded from the object. Bars $=300 \mu \mathrm{m}$

Figure 2 Numbers of small $(A)$ and large ( $B)$ myelinated fibres per T4 ventral root of controls (@), SDS ( $\square$ ) patients and other patients $(\Delta)$.

Figure 3 Transverse sections and diameter distributions of the T4 ventral roots of a control (C4) $(A, C)$ and a $S D S$ patient $(M 4)(B, D)$. Bars $=20 \mu \mathrm{m}$.
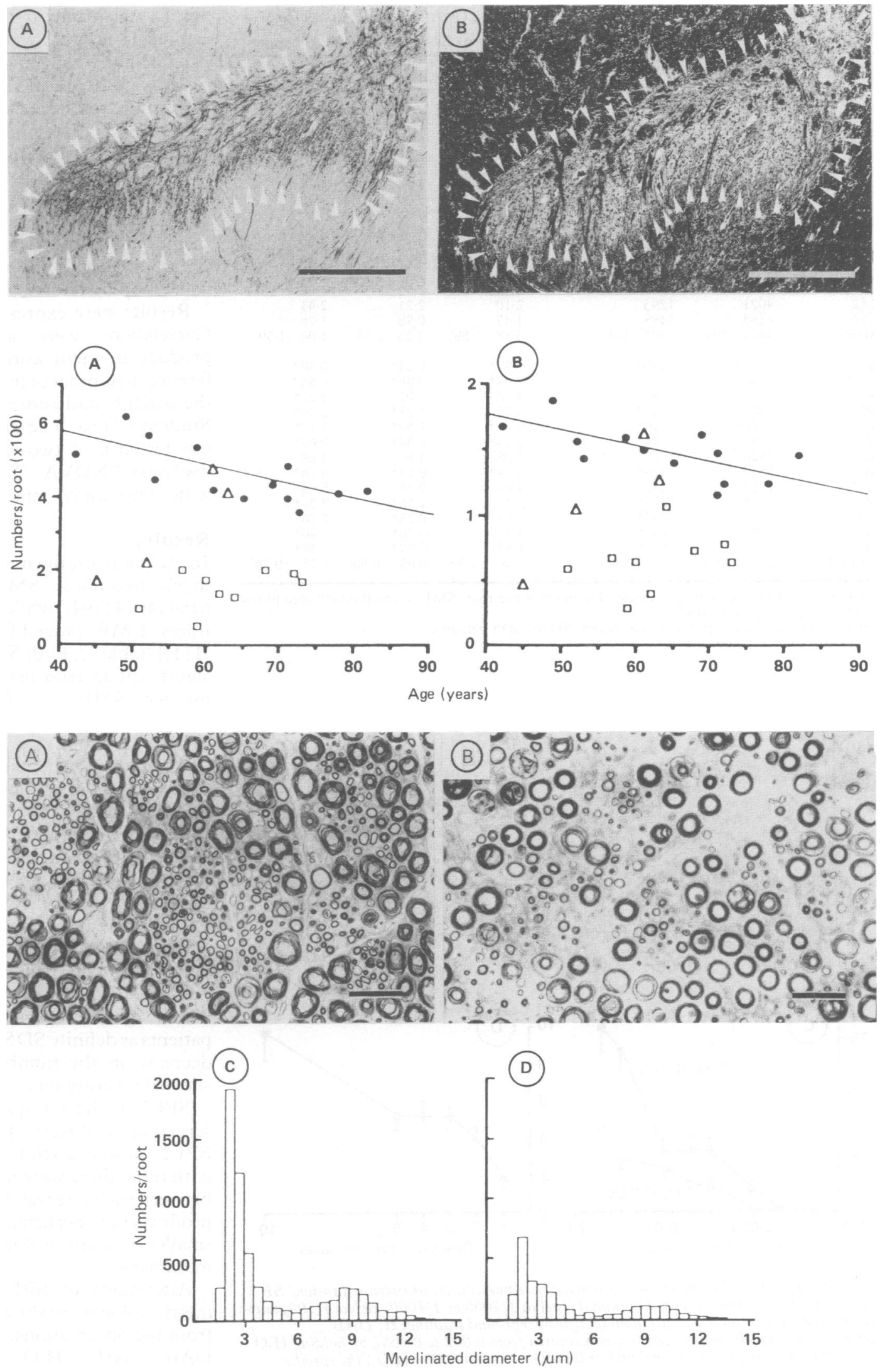

Figure 4 Effect of various postmortem intervals on SPLI in rats.

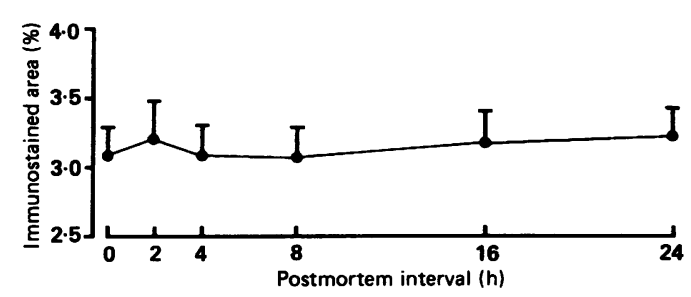

scope hardware, was stored in one image memory (KB-image memory) at $120 \times$ magnification. The image of the identical site of SP immunohistochemical preparation was stored in another image memory (SP-image memory) at the same magnification. On the TV image online with KB-image memory, the contour of laminae I + II was drawn as an overlay image 
Table 3 Numbers of myelinated fibres of the T4 ventral root and SPLI in laminae $I+I I$

\begin{tabular}{|c|c|c|c|c|c|}
\hline & \multicolumn{2}{|c|}{ Number of myelinated fibres } & \multicolumn{3}{|l|}{$S P L I(\% I a)$} \\
\hline & $S M F$ & $L M F$ & C6 & $T 4$ & $L 3$ \\
\hline $\begin{array}{l}\text { C } 1 \\
\text { C } 2 \\
\text { C } 3 \\
\text { C } 4 \\
\text { C } 5 \\
\text { C } 6 \\
\text { C } 7 \\
\text { C } 8 \\
\text { C } 9 \\
\text { C10 } \\
\text { C11 } \\
\text { C12 } \\
\text { C13 } \\
\text { Mean (SD) }\end{array}$ & $\begin{array}{l}5183 \\
6154 \\
5649 \\
4421 \\
5213 \\
4207 \\
3917 \\
4416 \\
5815 \\
3986 \\
3618 \\
4021 \\
4163 \\
4674(794)\end{array}$ & $\begin{array}{l}1720 \\
1834 \\
1547 \\
1426 \\
1569 \\
1505 \\
1432 \\
1610 \\
1516 \\
1205 \\
1248 \\
1293 \\
1488 \\
1492(171)\end{array}$ & $\begin{array}{l}5 \cdot 17 \\
7.90 \\
5 \cdot 41 \\
6 \cdot 45 \\
3.52 \\
4.08 \\
3.91 \\
4 \cdot 22 \\
2 \cdot 26 \\
1.86 \\
2 \cdot 14 \\
2 \cdot 10 \\
1.47 \\
3.88(1 \cdot 88)\end{array}$ & $\begin{array}{l}4.47 \\
3.81 \\
4.06 \\
5.14 \\
3.27 \\
5.45 \\
4.31 \\
2.16 \\
2.73 \\
2.49 \\
1.52 \\
2.21 \\
0.98 \\
3.23(1.34)\end{array}$ & $\begin{array}{l}4 \cdot 89 \\
4 \cdot 52 \\
6 \cdot 73 \\
6 \cdot 14 \\
3 \cdot 75 \\
5 \cdot 89 \\
3 \cdot 04 \\
3 \cdot 90 \\
2 \cdot 39 \\
2 \cdot 04 \\
5 \cdot 08 \\
2 \cdot 41 \\
1 \cdot 76 \\
4 \cdot 04(1 \cdot 59)\end{array}$ \\
\hline $\begin{array}{ll}M & 1 \\
M & 2 \\
M & 3 \\
M & 4 \\
M & 5 \\
M & 6 \\
M & 7 \\
M & 8 \\
M & 9 \\
M 10 \\
M 11 \\
\text { M12 } \\
\text { M13 (SD) } \\
\text { Mean (SD }\end{array}$ & $\begin{array}{l}1627^{\star} \\
984^{\star} \\
2103^{\star} \\
1983^{\star} \\
528^{\star} \\
1763^{\star} \\
4826 \\
1537^{\star} \\
4110 \\
1285^{\star} \\
2010^{\star} \\
1951^{\star} \\
1748^{\star} \\
2035^{\star}(1130)\end{array}$ & $\begin{array}{c}490^{\star} \\
583^{\star} \\
1082^{\star} \\
725^{\star} \\
279^{\star} \\
694^{\star} \\
1542^{\star} \\
429^{\star} \\
1250 \\
1071^{\star} \\
754^{\star} \\
793^{\star} \\
671^{\star} \\
797^{(339)}\end{array}$ & $\begin{array}{l}0 \cdot 97^{\star} \\
2 \cdot 84^{\star} \\
4 \cdot 18 \\
3 \cdot 74 \\
0 \cdot 79^{\star} \\
0 \cdot 24^{\star} \\
2 \cdot 08^{\star} \\
0 \cdot 74^{\star} \\
4 \cdot 63 \\
2 \cdot 27 \\
3 \cdot 62 \\
5 \cdot 31 \\
1.52 \\
2 \cdot 34^{\text {s }}\left(1.59^{\text {s }}\right)\end{array}$ & $\begin{array}{l}0 \cdot 24^{\star} \\
0.46^{\star} \\
3 \cdot 01^{\star} \\
1 \cdot 21^{\star} \\
1 \cdot 52^{\star} \\
0 \cdot 59^{\star} \\
4 \cdot 61^{\star} \\
0 \cdot 11^{\star} \\
2 \cdot 83^{\star} \\
1 \cdot 56^{\star} \\
0 \cdot 18^{\star} \\
0.46^{\star} \\
0.07^{\star} \\
0.68^{\mathrm{s}}\left(0.56^{\mathrm{s}}\right)\end{array}$ & $\begin{array}{l}0 \cdot 48^{\star} \\
0 \cdot 86^{\star} \\
3 \cdot 21^{\star} \\
2 \cdot 19^{\star} \\
1 \cdot 17^{\star} \\
0 \cdot 62^{\star} \\
3 \cdot 68 \\
0 \cdot 76^{\star} \\
5 \cdot 54 \\
2 \cdot 39^{\star} \\
2 \cdot 30 \\
0 \cdot 40^{\star} \\
0 \cdot 58^{\star} \\
1 \cdot 25^{\mathrm{s}}\left(0 \cdot 76^{\mathrm{s}}\right)\end{array}$ \\
\hline
\end{tabular}

Data on the T4 ventral root are expressed in number per root. SMF = small myelinated fibres; LMF = large myelinated fibres.

^Statistically significant $(p<0.05)$; S: Mean (SD) of SDS patients.

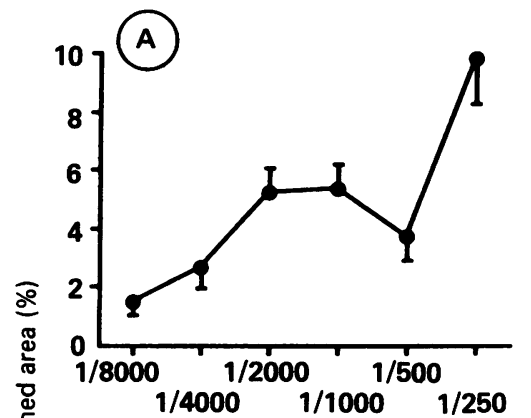

$\mathrm{SP}$ antiserum dilution
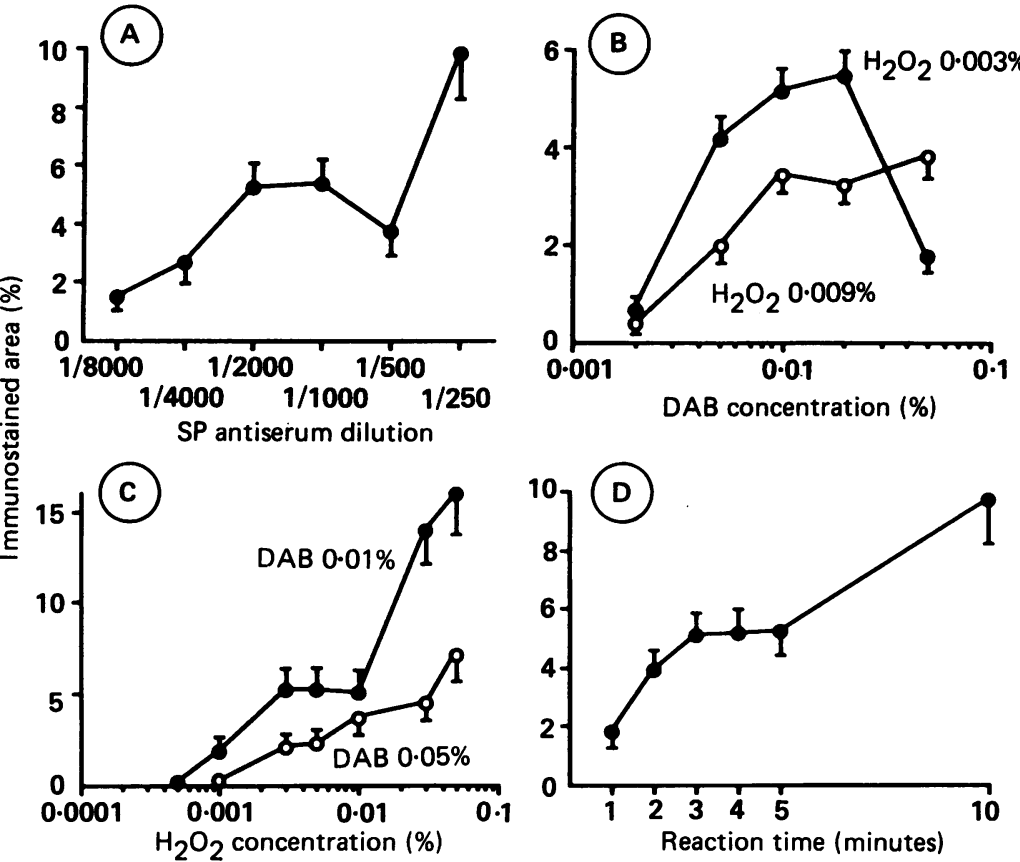

Figure 5 Effects of SP immunohistochemical parameters. A: antiserum dilution. SP specific reaction deposits reached maximal level at 1/2000 or 1/1000. Below 1/500, anti$S P$ showed a rapid increase with non-specific background staining. $B: D A B$ concentration. DAB concentration was increased from 0.002 to $0.05 \%$ by holding $\mathrm{H}_{2} \mathrm{O}_{2}$ concentration constant at either 0.003 or $0.009 \%$. With $0.003 \% \mathrm{H}_{2} \mathrm{O}_{2}$, the specific staining was maximal at $0.02 \% \mathrm{DAB}$. Beyond the $0.02 \% \mathrm{DAB}$, this $\mathrm{H}_{2} \mathrm{O}_{2}$

concentration was too low to allow an enzymatic reaction. In the presence of $0.009 \%$ $\mathrm{H}_{2} \mathrm{O}_{2}$, at 0.01 to $0.05 \% \mathrm{DAB}$, the specific staining was maximal but not saturated. $C$ : $\mathrm{H}_{2} \mathrm{O}_{2}$ concentration. $\mathrm{H}_{2} \mathrm{O}_{2}$ concentration was altered while $D A B$ concentration was held constant at two different levels. With $0.01 \% D A B$, the specific staining showed a linear increase to reach a maximum at 0.003 to $0.01 \% \mathrm{H}_{2} \mathrm{O}_{2}$. In more than $0.03 \% \mathrm{H}_{2} \mathrm{O}_{2}$, the area increased in a rapidly accelerating fashion due to the measurement of non-specific background feature. D: reaction time in DAB. Over the first phase, anti-SP $1 / 2000$ have a rapid increase in detected specific reaction products. After a short plateau phase which starts at three minutes and ends at five minutes, the immunostained area increased rapidly due to non-specific staining. $\mathrm{A}: D \mathrm{AB}=0.01 \%, \mathrm{H}_{2} \mathrm{O}_{2}=0.003 \%$, reaction time $=4$ minutes, $B, C$ : antibody dilution $=1 / 2000$, reaction time $=4$ minutes $D:$ antibody dilution $=1 / 2000, D A B=0.01 \%, \mathrm{H}_{2} \mathrm{O}_{2}=0.003 \%$. (fig 1). According to Rexed, ${ }^{27}$ the nerve cells of lamina II in a cat were either round or more often slightly elongated and the majority were $5-10 \times 5-10 \mu \mathrm{m}$ in size. Those of lamina III were more varied in size with the largest cell reaching $15 \times 18 \mu \mathrm{m}$ around. In $\mathrm{KB}$ preparation, the increasing number of fibres in lamina III contributed to a darker appearance as a whole than lamina II. This overlay image was subsequently transferred to the SP-image memory to fit the reference area. The executive programme with the above serial procedures was set up by referring to the second edition.

Results were expressed as the means (SD). Correlations were assessed by Pearson's product moment correlation test. The difference in number of myelinated fibres between the patients and controls was analysed by the Student's $t$ test. The difference of SPLI (\% Ia) was tested by a two-way analysis of variance (two-way ANOVA). The data were considered to be statistically significant at $p<0.05$.

\section{Results}

In the controls, the number (per root) of small myelinated fibres (SMF) ranged from 3618 to 6154 [4674 (794)] while that of large myelinated fibres (LMF) ranged from 1205 to 1834 [1492 (171)] (table 3). Both SMF and LMF showed a significant decrease in the number with increasing age $(\mathrm{SMF}: \mathrm{p}<0.05 ; \mathrm{R}=-0.63 ; \mathrm{Y}=$ 7257-40.8X, LMF: $\mathrm{p}<0.05 ; \mathrm{R}=-0.66 ; \mathrm{Y}=$ 2109-9.7X) (fig 2).

Of 13 MSA patients, 11 showed a significant decrease in the number of both SMF ( $p<$ 0.01 ) and LMF (p $<0.01)$. The decrease was more prominent in SMF than in LMF (figs 2, 3 ). The variation in the number among all patients was from 528 to 4826 [2035 (1130)] in SMF and from 279 to 1542 [797 (339)] in LMF (table 3). Because two (M1, M3) of these 11 patients did not show any definite autonomic failure (M1: no orthostatic hypotension, M3: vesicorectal disturbance is not specific to autonomic sign), we diagnosed the remaining nine patients as definite SDS. Two cases without any decrease in the number of SMF (M7, M9) showed no autonomic dysfunction.

SPLI in the rat spinal cord was well preserved up to at least 24 hours (fig 4). Although SPLI showed a tendency to increase slightly with time, there were no significant differences between each interval. SP-like immunoreactive products of superficial dorsal horn in rats were smaller in shape and more homogeneous than in humans.

Alterations of SPLI dependent on parametric value were shown in fig 5 . As expected from the observations, anti-SP $1 / 2000,0.01 \%$ DAB, $0.003 \% \mathrm{H}_{2} \mathrm{O}_{2}$ and a reaction for 4 minutes are optimal values for the image analysis on the SP immunohistochemical preparations.

Figure 6 showed representative SP immunostaining of the same cases $(\mathrm{C} 4, \mathrm{M} 4)$ as in fig 2 . In the control, SP immunolabelling was seen in abundance in lamina $I$ and the dorsal parts of lamina II(A), and showed various appearances in shape, that is, fine granular, vesicular and linear varicositous $(\mathrm{C})$. In the 
Figure 6 Representative $S P$ immunostaining and its details at higher magnification in the superficial dorsal horn. A, $C$ : a control (C4), $B, D$ : a patient (M4). Bars for $A, B=200 \mu \mathrm{m}$, bars for $C, D=50 \mu \mathrm{m}$.
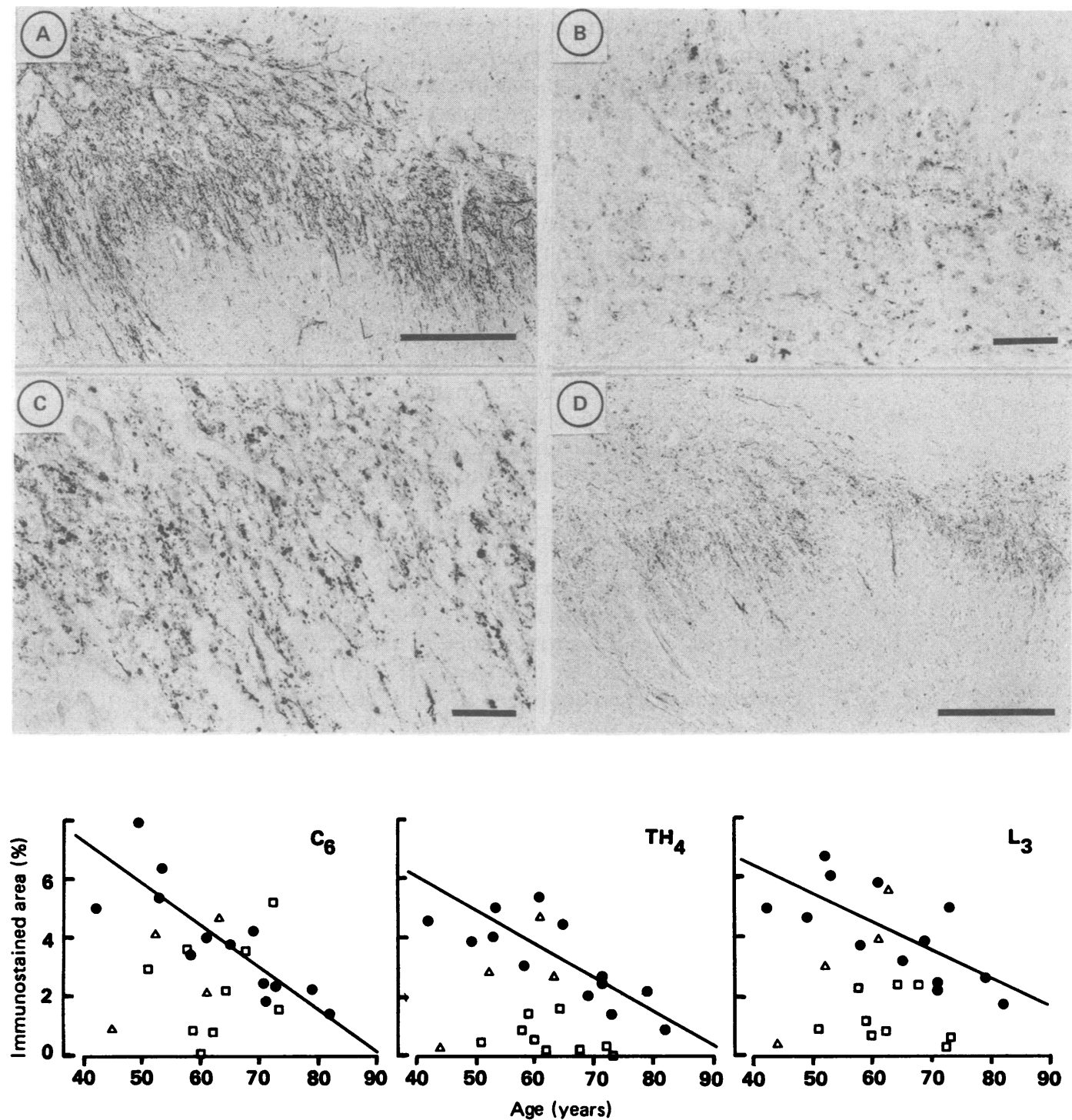

patient, SP-positive products were severely depleted (B, D).

As shown in table 3, the controls showed wide variations of SPLI ( $\%$ Ia) at three different levels of spinal cord. There were significant reductions in SPLI with increasing age at all three levels (C6: $\mathrm{p}<0.05 ; \mathrm{R}=-0.86 ; \mathrm{Y}=$ 12.68-0.14X, T4: $\mathrm{p}<0.05 ; \mathrm{R}=-0.78 ; \mathrm{Y}=$ 8.98-0.090X, L3: $\mathrm{p}<0.05 ; \mathrm{R}=-0.69 ; \mathrm{Y}=$ $10 \cdot 12-0 \cdot 10 \mathrm{X}$ ( (fig 7). The slopes were not significantly different between the three levels. SPLI showed no significant correlation with sex, postmortem interval and fixation length.

In the patients with SDS, SPLIs (\% Ia) were also varied. The range of \% Ia in SDS patients overlapped with those of the controls for the most part at the $\mathrm{C} 6$ level, and for a lesser part at the T4 and L3 level. But when adjusted for age (two way ANOVA), SPLIs in all SDS patients and one other patient (M1), with a significant decrease of myelinated fibres, were significantly decreased at the T4 $(p<0.05)$ and L3 (p < $0.05)$ levels except for one (M11) at the L level (fig 7). SPLI of SDS patients did not correlate statistically with the duration either of the disease or of the autonomic dysfunction.

\section{Discussion}

We performed the morphometric study to diagnose definite SDS patients. It is generally assumed that small and large myelinated fibre counts in the thoracic ventral root are simple and reliable methods to evaluate the loss of preganglionic autonomic neurons in IML, and alpha and gamma motor neurons in the ventral horn, respectively.

SPLI on the tissue section of autopsied material alters depending on either the degradation of SP itself before fixation or autolysis of the tissue which influences the immobilisation of SP by fixatives. SP in the brain was stable for at least 72 hours after death at room temperature in a biochemical study using a radioimmunoassay technique. ${ }^{28}$

Degradation of SP is not considered in our cases with postmortem intervals of shorter than 16 hours. The degree of autolysis is different for each material depending on postmortem handling, especially necropsy delay, even if the material is stored in a refrigerator at a constant temperature. The effects therefore of necropsy delay on SP immunostain were examined on rat spinal cords under similar postmortem condi- 
tions as humans and good preservation of SPLI up to 24 hours was confirmed. Once optimal immunohistochemical conditions were established, it was possible to compare the intensity of SPLI between each autopsied material.

SP quantitative data on the controls in this study confirmed the age-related decrease of SPLI in the superficial dorsal horn of humans. In view of the age-related decrease in the number of nerve cells of the first sacral ganglia, ${ }^{29}$ this decrease of SPLI may be due to an agerelated decrease in the number of SP-nergic primary afferent neurons rather than the decrease of SP content per neuron. Emson ${ }^{28}$ described the content of SP in normal human brains as not significantly affected by age. This disparity is probably due to the difference of the regions studied.

Our study is the first immunohistochemical report demonstrating the decrease of SP in the superficial dorsal horn of SDS patients, which were definitely diagnosed with the morphometry of spinal ventral roots. This finding agrees with a study by Anand et al, ${ }^{30}$ who revealed a marked depletion of SP in the spinal dorsal horn of four MSA patients by radioimmunoassay. The pain sensation of our patients, however, was almost spared entirely as in previous reports. ${ }^{1518}$ The most likely interpretation of the results is that the loss of SP is not sufficient to affect nociception in a detectable manner. We also counted the number of myelinated fibres in the dorsal roots, but there was no significant decrease in number in SDS patients (not shown). Unmyelinated Cfibre cannot be discriminated by this method. Another plausible explanation is that the decrease of SP immunostaining in the dorsal horn is caused by the loss of non-nociceptive SP-containing visceral afferents. SP is also known to occur in interneurons of the superficial dorsal horn. ${ }^{2}$ Moreover, some A delta sensory fibres contain SP. ${ }^{6}$ The ratio of SP content in these three populations has not been fully examined. We also performed a similar quantitative study about calcitonin-gene related peptide (CGRP), a neuropeptide colocalising with SP in neurons of dorsal root ganglia, ${ }^{31}$ but a decrease of CGRP was not detected in these SDS patients. The decreased concentration of SP in the cerebrospinal fluid of SDS patients may reflect the disorder of SPcontaining primary sensory and/or intraspinal neurons. ${ }^{32}$ Further study will be needed to distinguish between these alternatives.

As for SP in the primary sensory neurons, it is of particular interest that SP immunoreactive fibres of a sensory nature pass through the sympathetic ganglion with SPLI varicose network surrounding postganglionic neurons ${ }^{33-36}$ and SP plays a transmitter role in the sympathetic ganglion. ${ }^{37}$ These suggest an interaction between the autonomic disorder and the depletion of SP in primary sensory neurons of SDS patients.

This study has shown that a quantitative immunohistochemical evaluation of SPLI can be applied to human material at necropsy and SPLIs are considerably depleted in the superficial dorsal horn of the patients with SDS.
We thank Dr Akazawa and Professor Y Nose, Department of Medical Informatics, Kyushu University Hospital, for the statistical treatment of the data; $K$ Hatanaka and $M$ Yoneda for excellent technical assistance; and B T Quinn for his comments on the manuscript. We acknowledge the assistance of Carl Zeiss Corporation, Japan, for help with the computer-assisted image analyser.

1 Cuello AC. Substance P: naturally occurring transmitter in human spinal cord. Lancet 1976;13:1054-6.

2 Hökfelt T, Ljungdahl A, Terenius L, Elde R, Nilsson G. Immunohistochemical analysis of peptide pathways possibly related to pain and analgesia: enkephalin and substance P. Proc Natl Acad Sci USA 1977;74:3081-5.

3 Frederickson RCA, Burgis V, Harrell CE, Edwards JD. Dual actions of substance $P$ on nociception: Possible role of endogenous opioids. Science 1978;199:1359-62.

4 Oehme P, Hilse H, Morgenstern E, Göres E. Substance P. Does it produce analgesia or hyperalgesia? Science 1980; 208:305-7.

5 Takahashi T, Otsuka M. Regional distribution of substance $P$ in the spinal cord and nerve roots of the cat and the effect of dorsal root section. Brain Res 1975;87:1-11.

6 Jessell TM, Iversen LL, Cuello AC. Capsaicin-induced depletion of substance $P$ from primary sensory neurons. Brain Res 1978;152:183-8.

7 Jansco G, Hökfelt T, Lundberg JM, et al. Immunohistochemical studies on the effect of capsaicin on spinal and medullary peptide and monoamine neurons using antisera to substance $P$, gastrin/CCK, somatostatin, VIP, enkephalin, neurotensin anc 5-hydroxytryptamine. J Neurocytol 1981;10:963-80.

8 Jessell TM, Tsunoo A, Kanazawa I, Otsuka M. Substance P depletion in the dorsal horn of rat spinal cord after section depletion in the dorsal horn of rat spinal cord after section
of the peripheral process of primary sensory neurons. of the peripheral process of

9 Di Giulio AM, Mantegazza P, Dona M, Gorio A. Peripheral nerve lesions cause simultaneous alterations of substance $P$ and enkephalin levels in the spinal cord. Brain Res 1985 342:405-8.

10 Light AR, Trevino DL, Perl ER. Morphological features of functionary defined neurons in the marginal zone and substantia gelatinosa of the spinal dorsal horn. J Comp Neurol 1979;186:151-72

11 Sugiura Y, Lee CL, Perl ER. Central projections of identified, unmyelinated $(C)$ afferent fibers innervating mammalian skin. Science 1986;234:358-61.

12 Baker RP, Vaughn JE, Slemmon JR, Salvaterra PM, Roberts E, Leeman SE. The origin, distribution and synaptic relationship of substance $\mathbf{P}$ axons in rat spinal cord. J Comp Neurol 1979;184:331-52.

13 Chan-Palay V, Palay SL. Immunocytochemical identification of substance $P$ cells and their processes in rat sensory tion of substance P cells and their processes in rat sensory ganglia and their terminals in the spinal cord: Light
microscopic studies. Proc Natl Acad Sci USA 1977;74: microscopic

14 Pearson J, Brandeis L, Cuello AC. Depletion of substance Pcontaining axons in substantia gelatinosa of patients with diminished pain sensitivity. Nature 1982;295:61-3.

15 Shy GM, Drager GA. A neurological syndrome associated with orthostatic hypotension. Archiv Neurol 1960;2: 511-27.

16 Johnson RH, Lee GJ, Oppenheimer DR, Spalding JMK. Autonomic failure with orthostatic hypotension due to intermediolateral column degeneration. $Q J$ Med 1966; 35:276-92.

17 Fichefet JP, Sternon JE, Franken L, Domanet JC, Vanderhaeghen JJ. Etude anatomo-clinique d'um cas d'hypotension orthostatique "idiopathique". Acta Cardiol 1965; 20:332-48.

18 Graham JG, Oppenheimer DR. Orthostatic hypotension and nicotine sensitivity in a case of multiple system atrophy. J Neurol Neurosurg Psychiatry 1969;32:28-34.

19 Low PA, Thomas JE, Dyck PJ. The splanchnic autonomic outflow in Shy-Drager syndrome and idiopathic orthostatic hypotension. Ann Neurol 1978;4:511-4.

20 Sobue G, Hashizume Y, Ohya M, Takahashi A. Shy-Drage syndrome: neuronal loss depends on size, function, and topography in ventral spinal outflow. Neurology 1986 36:404-7.

21 Galassi G, Nemni R, Baraldi A, Gibertoni M, Colombo A. Peripheral neuropathy in multiple system atrophy with autonomic failure. Neurology 1982;32:1116-21.

22 Tohgi $H$, Tabuchi $M$, Tomonaga $M$, Izumiyama $N$. Selective loss of small myelinated and unmyelinated fibers in Shy-Drager syndrome. Acta Neuropathol (Berl) 1982;57: 282-6.

23 Low PA, Dyck PJ. Splanchnic preganglionic neurons in man: II. Morphometry of nyelinated fibers of $T_{7}$ ventral man: II. Morphometry of nyyelinated fibers of $\mathrm{T}_{7}$ ventral

24 Chopra IJ. A radioimmunoassay of measurement of 3,3' triiodothyronine (reverse $T_{3}$ ). J Clin Invest 1974;54: 583-92.

25 Talian JC, Olmsted JB, Goldman RD. A rapid procedure for preparing fluorescein-labeled specific antibody from whole antiserum: Its use in analyzing cytoskeletal architecture. $J$ Cell Biol 1983;97:1297-82.

26 Gross DS, Rothfeld JM. Quantitative immunocytochemistry of hypothalamic and pituitary hormones. $J$ Histochem Cytochem 1985;33:11-20.

27 Rexed B. The cytoarchitectonic organization of the spinal cord in the cat. J Comp Neurol 1952;96:415-95.

28 Emson PC. Neuropeptides and the pathology of Huntington's disease. Prog Brain Res 1986;66:91-105. 
29 Gardner E. Decrease in human neurons with age. Anat $R e c$ 1940;77:529-36.

30 Anand P, Bannister R, McGregor GP, Ghatei MA, Mulderry PK, Bloom SR. Marked depletion of dorsal spinal cord substance $\mathbf{P}$ and calcitonin gene-related peptide with intact skin flare responses in multiple system atrophy. $J$ Neurol Neurosurg Psychiatry 1988;51:192-6.

31 Gibbins IL, Furness JB, Costa M, MacIntyre I, Hillyard CJ, Girgis S. Co-localization of calcitonine gene-related peptide-like immunoreactivity with substance $P$ in cutaneous, vascular and visceral sensory neurons of guinea pigs. Neurosci Lett 1985;57:125-30.

32 Nutt JG, Mroz EA, Leeman SE, Williams AC, Engel WK, Chase TN. Substance P in human cerebrospinal fluid: reductions in peripheral neuropathy and autonomic dysreductions in peripheral neuropathy
function. Neurology 1980;30:1280-5.

33 Gamse R, Wax A, Zigmond RE, Leeman SE. Immunoreactive substance $P$ in sympathetic ganglia: Distribution and sensitivity towards capsaicin. Neuroscience 1981; 6:437-41.

34 Helen P, Panula P, Yang HYT, Hervonesn A, Rapoport SI. Location of substance P-, bombesin-, gastrin-releasing peptide, $\left[\mathrm{Met}^{5}\right]$ enkephalin- and $\left[\mathrm{Met}^{5}\right]$ enkephalin-Arg ${ }^{6}-$ $\mathrm{Phe}^{7}$-like immunoreactivities in adult human sympathetic ganglia. Neuroscience 1984;12:907-16.

35 Hökfelt T, Elfvin LG, Schultzberg M, Goldstein M, Nilsson G. On the occurrence of substance P-containing fibers in sympathetic ganglia: Immunohistochemical fibers in sympathetic ganglia: Im

36 Matthews MR, Cuello AC. Substance P-immunoreactive peripheral branches of sensory neurons innervate guinea pig sympathetic neurons. Proc Natl Acad Sci USA 1982;

37 Konishi S, Tsunoo A, Otsuka $M$. Substance $P$ and noncholinergic excitatory synaptic transmission in guinea pig sympathetic ganglia. Proc J Acad 1979;55:525-30. 